\title{
Prevalence of Dental Caries among the Population of Gwalior (India) in Relation of Different Associated Factors
}

\author{
Abdul Arif Khan ${ }^{a}$ \\ Sudhir K. Jain ${ }^{b}$ \\ Archana Shrivastav ${ }^{a}$
}

\section{ABSTRACT}

Objectives: India is unique in entire world due to variety of dietary habits in population. Many people of India follow totally vegetarian life style through their entire life time due to some religious and cultural reasons. Present study tried to analyze the role of different factors in the occurrence of dental caries including dietary habit.

Methods: Persons suffering with dental caries were examined for the type of dental caries in relation to different factors. Dental examination was performed and patients were asked a questionnaire and the data was recorded and analyzed.

Results: Incidence of dental caries was higher in female. High number of dental caries patients was observed among vegetarian population. 21-30 year age group was found to be most infected with dental caries.

Conclusions: This study can be helpful to analyze respective role of different dietary factors including protein rich diet, age, gender etc. on the prevalence of dental caries, which can be helpful to counteract the potential increase in the cases of dental caries and to design and plan preventive strategies for the persons at greatest risk. (Eur J Dent 2008;2:81-85)

Key words: Dental caries; Periodontitis; Orodental; Dietary habit; Saliva.

\section{INTRODUCTION}

Dental caries and related oral diseases like gingivitis and periodontitis are most common oral

Department of Microbiology, College of Life Sciences, Cancer Hospital \& Research Institute, Gwalior (M.P.), INDIA

b School of Studies in Microbiology, Vikram University, Ujjain (M.P.), INDIA

- Corresponding author: Dr. Abdul Arif Khan Assist. Professor, Department of Microbiology, College of Life Sciences, Cancer Hospital \& Research Institute, Gwalior (M.P.) INDIA

Phone: $+917514027708,+919406500814$

E-mail: abdularifkhandgmail.com diseases throughout the world. The prevalence of these diseases is continuously increasing with change in dietary habit of peoples and increased consumption of sugar. ${ }^{1}$ The prevalence of dental caries is approximately $60 \%-65 \%$ in India.2, 3 However, this disease is greatly affected by many factors other than sugar consumption.

In order to understand the factors responsible for dental caries immunity and susceptibility, the use of epidemiological methodology as an effective research tool has been documented in many previous studies. 4,5 India is unique in the entire world, in concern with the dietary habit of 
population. Many people are totally vegetarian throughout their entire life due to some religious reasons. It gives a great opportunity to study the effect of vegetarian and non vegetarian diet (mixed diet) over the incidence of dental caries. This study looked at the pattern of caries among patients attending Dentistry department of Gajra Raja Medical College, Gwalior and various other local district hospitals of Gwalior, in relation to type of caries, age group and gender, dietary habit most affected.

It has been recommended by many scientists that to counteract the potential increase in the prevalence of dental caries in developing nations, preventive and oral health programs can be planned and implemented and targeted to those at the greatest risk of dental caries. ${ }^{6}$ So the present study was performed in order to analyze these factors, which can help to plan preventive strategies for the population at greater risk for the development of dental caries

\section{MATERIALS AND METHODS}

The present study was comprised of 104 cases. All these cases were selected out of the patients attending the Dentistry department of local dental hospitals of Gwalior. Individuals were randomly selected from list of patients and every single individual had equal chance of selection. So, simple probability random sampling was used in order to get information about prevalence of dental caries in local area. However, sample size was small but proper care was taken to make sample, as representative of patient's population. The persons were examined in the local dental clinics and hospitals, while seated on an ordinary chair, in broad day light facing away from direct sunlight. Ethical approval for the study was taken from, college ethical committee.

The subjects for this study were people between 5-72 years of age. The dental examination was performed with the help illumination devices and data were recorded and analyzed. The type of caries, as well as the duration of symptoms was asked from patients as a questionnaire. However dental caries is a chronic disease and take a long time to de-mineralize the dental enamel, but the patients were asked for the duration, from when they are feeling visual symptoms like demineralization and pain.
The examination of patients involved the sequential assessment of teeth beginning from 1 to 32. All exposed and accessible surface were examined for the dental caries. Mirror and explorer were also used during the examination. Compressed air was also used to dry teeth and to remove debris in order to allow better visual examination. Trans-illumination device was also used in order to detect carious enamel. The instruments used were sterilized after every single use. The site infected with dental caries was recorded. Patient age and location were also recorded in order to infer the status of disease in locality. Oral hygiene by means of tooth brushing was also asked as questionnaire.

\section{RESULTS}

During this study, we tried to analyze the number of persons affected with dental caries in different gender, age, dietary habit, among the patient studied. The occurrence of dental caries was found to be slightly higher in females (Table 1). We also tried to analyze the most frequent type of caries in the patients studied (Tables 2 and 3). Beside it, we also compared the type of dental caries in person with different dietary factor (Table 4). Incidence study found the occurrence and factor responsible for dental caries. The incidence among different age group shown the occurrence of dental caries among 21-30 year population (Table 5).

\section{DISCUSSION}

Dental caries is a multi-factorial disease influenced by many factors including age, sex, ${ }^{7}$ diet, microorganisms, trace elements, saliva, genetic predisposition and tooth morphology. ${ }^{8,9}$ In the present study, we find slightly high number of caries cases among females $(P=0.510)$ in comparison to males $(P=0.490)$ suggesting that females are more prone to caries than males (Table 1). This can be attributed to number of facts, including early teeth eruption in girls in comparison to boys, differences in dental attendance due to lack of financial independence on the part of females and

Table 1. Percent infection with dental caries (in different genderl among the patients studied.

\begin{tabular}{cc}
\hline Male & Female \\
\hline $49.51 \%(51)$ & $51.45 \%(53)$ \\
\hline
\end{tabular}


fear of dentist among male and female and also to difference in dietary pattern between housewives and working man. ${ }^{10-12}$

Among the type of most frequent caries in the patients, we found the occlusal pits and fissure caries ( $P=0.808$ ) as highly prevalent (Tables 2 and 3). The smooth surface caries $(P=0.125)$ ranked second followed by root caries $(P=0.058)$ and recurrent caries $(P=0.010)$ at third and fourth position respectively. Highest prevalence of occlusal pits and fissure caries can be correlated with the architecture of these sites, which is more retentive to carry food substances and is not fully exposed to flushing action of saliva. The biofilm tends to form and mature in these locations on the tooth including approximal surface cervical to the contact point, and along the gingival margin especially during eruption. These areas are relatively protected from mechanical wear by tongue, cheeks, abrasive food, and tooth brushing. Thus, these are the sites where caries lesions may become visible. ${ }^{13}$ Similar observations have been obtained by many scientists indicating that, there is a relative lack of proper preventive procedures for such type of caries. ${ }^{14}$ The smooth surface caries is generally correlated with the long term poor oral hygiene and long term accumulation of plaque, ${ }^{15}$ which is a very common practice among the rural area due to lack of awareness regarding the dental hygiene.

Root surface caries is usually related with poor health of gingival area, ${ }^{16}$ we have found relatively high occurrence of root caries among males including tobacco chewers, which usually results in unhealthy gingiva, and it might result in dental caries in these areas. But we found least number of recurrent caries patients which was female; this can be well correlated with the fact that, persons who experience caries first, usually become aware for the prevention of caries. In Indian scenario females are still not in contact with this information due to male dominating society and lack of financial independence among females. But, it has been reported that, condition of oral and dental health is relatively improving in developing countries. ${ }^{17}$

Among the persons studied with different dietary habit, we found the highest number of caries patients with vegetarian dietary habit $(P=0.856)$ followed by vegetarian plus tobacco user ( $P=0.077)$ and non vegetarian (Mixed diet) $(P=0.067)$, respectively (Table 4). It has been verified that dental caries is a process due to formation of acid by fermentation of sugar through acidogenic bacteria that lead to decalcification of dental enamel. ${ }^{18}$ But this acid is usually neutralized with the buffering action of saliva ${ }^{19}$ and the dental caries is prevented. When fermentable carbohydrate was not added to the saliva, putrefaction replaced fermentation, alkalinity replaced acidity, and no decalcification is usually observed. ${ }^{20}$ Putrefaction is the result of protein consumption, so it might be suggested that the persons who consume plenty of protein rich food in comparison to sugar, will develop less amount of acid in their mouth and relatively be protected from dental caries. It might

Table 2. Percent occurrence of different type of caries.

\begin{tabular}{rccc}
\hline Root caries & Recurrent caries & Smooth surface caries & Occlusal pits and fissure caries \\
\hline $5.76 \%$ & $0.96 \%$ & $12.50 \%$ & $80.76 \%$ \\
\hline
\end{tabular}

Table 3. Percent occurrence of different type of caries in male ( $\hat{)})$ and female (ㅇ).

\begin{tabular}{cccccccc}
\hline \multicolumn{4}{c}{ Male (ふे) } & \multicolumn{4}{c}{ Female (申) } \\
\hline RC & RK & SC & OFC & RC & RK & SC & OFC \\
\hline $5(9.80 \%)$ & $0(0 \%)$ & $8(15.6 \%)$ & $38(74.5 \%)$ & $1(1.88 \%)$ & $1(1.88 \%)$ & $5(9.43 \%)$ & $46(86.7 \%)$ \\
\hline
\end{tabular}

RC: Root caries; RK: Recurrent caries; SC: Smooth surface caries; OFC: Occlusal pits and fissure caries.

Table 4. Occurrence of dental caries in the patients with different dietary habit.

\begin{tabular}{cccc}
\hline Vegetarian & Non vegetarian & $\begin{array}{c}\text { Vegetarian and } \\
\text { tobacco user }\end{array}$ & $\begin{array}{c}\text { Non vegetarian and } \\
\text { tobacco user }\end{array}$ \\
\hline $89(85.57 \%)$ & $7(6.73 \%)$ & $8(7.69 \%)$ & $0(0 \%)$ \\
\hline
\end{tabular}


be the reason for less number of cases among the non vegetarian (Mixed diet) population.

Among the different age group studied we found highest number of cases in between 21 to 30 year peoples (Table 5). It might be suggested that, the development of dental caries is a long term process, and the habit of sugar consumption is relatively high among the teenagers (In the form of chocolates and other sticky sugar rich food), but the peoples usually don't attend the hospitals, until and unless they feel unbearable pain in the mouth. So we have found most number of dental caries patients among this group. But the number of cases continually increased up to the age of 21-30 ( $P=0.269)$ and later on these cases got declined. But a more detailed and long term study is required to analyze the long term effect of age on the development of dental caries among the population. However caries is traditionally reported as DMFS (Decayed, missing filled surface)/ DMFT (Decayed, missing filled teeth) index, but this index neither a ratio nor a percentage and does not reflect the part of population having caries. ${ }^{21}$ Beside it this index does not work with the study of type of caries and many other issues, ${ }^{22}$ so we did not analyzed this index during our study. These results on prevalence of dental caries can be correlated with other findings. ${ }^{23}$

This data can be helpful for estimating the condition of this disease in local population and to give a reliable measure over the manpower requirement and oral health management costs.

Table 5. Occurrence of dental caries in different age group.

\begin{tabular}{ccc}
\hline Sr. No. & $\begin{array}{c}\text { Age group } \\
\text { (Years) }\end{array}$ & $\begin{array}{c}\text { Number and percentage } \\
\text { of patients }\end{array}$ \\
\hline 1 & $0-10$ & $2(2.88 \%)$ \\
2 & $11-20$ & $11(10 \%)$ \\
3 & $21-30$ & $28(26.92 \%)$ \\
4 & $31-40$ & $20(19 \%)$ \\
5 & $41-50$ & $17(16.34 \%)$ \\
6 & $51-60$ & $15(14.1 \%)$ \\
7 & $61-70$ & $8(7.69 \%)$ \\
8 & $71-80$ & $3(2.88 \%)$ \\
\hline
\end{tabular}

\section{CONCLUSIONS}

Epidemiology of any disease is a very helpful tool to assess the actual status of the disease among population. The unique condition of India provides a very beautiful condition for the study of different factors associated with dental caries. However this work is a small effort towards understanding of factors associated with dental caries, but this study may give a clue regarding possible role of protein rich non vegetarian (or mixed) dietary habit in prevention of dental caries. However more detailed collaborative study is required to infer actual role of these associated factor in dental caries etiology. The data can be helpful for designing the preventive measures against dental caries on the basis of factors associated with it.

\section{REFERENCES}

1. Saini S, Aparna, Gupta N, Mahajan A, Arora DR. Microbial flora in orodental infections. Indian $J$ Med Microbiol 2003;21:111-114.

2. Shouri KL. Dental caries in Indian children. Indian J Med Res 1941;29:709-722.

3. Ramchandran K, Rajan BP, Shanmungan S. Epidemiological studies of dental disorders in Tamilnadu population, prevalence of dental caries and periodontal diseases. $J$ Indian Dent Assoc 1973;45:65-70.

4. Hadjimarkos DM. The epidemiological method as a research tool in dental caries. J Canad Dent Assoc 1956;22:657.

5. Gordon JE. Dental problems in an epidemiological perspective. Am J Public Health 1959;49:1041.

6. Ismail AL, Tanzer JM, Dingle Jl. Current trends of sugar consumption in developing societies. Community Dent Oral Epidemiol 1997;25;438-445.

7. Addy M, Dummer PMH, Hunter MI, Kigdon A, Shaw WC. The effect of tooth brushing frequency, tooth brushing hand, sex and social class on the incidence of plaque, gingivitis and pocketing in adolescent. A longitudinal cohort study. Community Dev Health 1990;7:237-247.

8. Dash JK, Sahoo PK, Bhuyan SK, Sahoo SK. Prevalence of dental caries and treatment needs among children of Cuttack (Orissa). J Ind Soc Prev Dent 2002;20:139-143.

9. Kumar M, Chandu GN, Shafiulla MD. Oral health status and treatment needs in institutionalized psychiatric patients: one year descriptive cross sectional study. Indian J Dent Res 2006;17:171-177.

10. Silverstone LM, Johnson NW, Hardie JM, Williams RAD. Dental caries, Aetiology, Pathology and Prevention $1^{\text {st }}$ ed. London: Macmillan Press 1981:26-27.

11. Kutesa A, Mwanika A, Wandera M. Pattern of dental caries 
in mulago dental school clinic, Uganda. African Health $S c i$ 2005;5:65-68.

12. Nanda A, Ingle NA. Study of fear in dentistry. J Ind Dent Accos 2002;73:104-110.

13. Kidd EAM, Fejerskov 0 . What constitutes dental caries? Histopathology of carious enamel and dentin related to the action of cariogenic biofilm. J Dent Res 2004;83:C35-C38.

14. Manji F, Mosha H, Frencken J. Tooth and surface pattern of dental caries in 12 year old urban children in East Africa. Community Dent Oral Epidemiol 1986;14:99-110.

15. Summit, JB, Robbins JW, Schwartz RS. Fundamentals of Operative Dentistry: A Contemporary Approach. $2^{\text {nd }}$ ed. Carol Stream, Illinois, Quintessence Publishing Co, Inc, 2001:31

16. Banting, D.W. "The Diagnosis of Root Caries" Presentation to the National Institute of Health Consensus Development Conference on Diagnosis and Management of Dental Caries Throughout Life, in pdf format, hosted on the National Institute of Dental and Craniofacial Research. 2001:19

17. Mistry K. Establishment of community dental health units in developing countries. J Ind Dent Assoc 1982;54:361-366.

18. Tinanoff N, Palmer CA. Dietary determinants of dental caries and dietary recommendations for preschool children. J Public Health Dent 2000;60:197-206.

19. Bardow A, Moe D, Nyvad B, Nauntofte B. The buffer capacity and buffer systems of human whole saliva measured without loss of $\mathrm{CO}_{2}$. Arch Oral Biol 2000;45:1-12.

20. Miller WD. The microorganisms of the human mouth, Philadelphia, PA, 1890, SS White and Co. Reprinted, Basel: Karger. 1973

21. Alanen P. Remarks on the use of some basic epidemiological concepts in dentistry. Proc Finn Dent Soc 1991;87:209-215.

22. Ettingor RL. Epidemiology of dental caries: A broad review. Cariology 1999:43:679-694.

23. Dhar V, Jain A, Van Dyke TE, Kohli A. Prevalence of dental caries and treatment needs in the school-going children of rural areas in Udaipur district. J Indian Soc Pedod Prev Dent 2007;25:119-121 